\title{
The effect of implantoplasty on dental implant fracture resistance: a systematic review
}

\author{
Rayner Goh ${ }^{1}$, Andrew Tawse-Smith ${ }^{1 *}$, Momen Atieh ${ }^{2,3}$, Warwick Duncan ${ }^{1}$, Sunyoung $\mathrm{Ma}^{4}$, Kai \\ Chun $\mathrm{Li}^{1}$ \\ ${ }^{1}$ Sir John Walsh Research Institute, Faculty of Dentistry, University of Otago, Dunedin, New Zealand \\ ${ }^{2}$ Department of Oral Diagnostic and Surgical Sciences, Hamdan Bin Mohammed College of Dental Medicine, \\ Mohammed Bin Rashid University of Medicine and Health Sciences, Dubai Healthcare City, Dubai, United Arab \\ Emirates \\ ${ }^{3}$ Honorary Associate Professor, Sir John Walsh Research Institute, Faculty of Dentistry, University of Otago, \\ Dunedin, New Zealand \\ ${ }^{4}$ Department of Oral Rehabilitation, Faculty of Dentistry, University of Otago, Dunedin, New Zealand
}

\begin{abstract}
An increase in dental implant placements in recent years has seen a growth in the reported cases of post-operative complications such as peri-implantitis. One of the available treatment modalities to overcome such complications is implantoplasty. Although this procedure is not new, the long-term effect of implantoplasty has not been addressed extensively. The aim of this systematic review was to investigate the change in fracture resistance of dental implants after implantoplasty. Three electronic databases and reference lists of included studies were searched to assess the potential effect of implantoplasty on implant fracture resistance. Titles and abstracts were screened by two reviewers in parallel. The extracted information regarding implant fracture resistance was reported based on the guidelines set by the Preferred Reporting Items for Systematic Reviews and Meta-analyses (PRISMA) statement. A total of 56 studies were identified, of which, nine studies were included. Narrow platform implants $(<3.75 \mathrm{~mm})$ were more susceptible to fracture following implantoplasty compared to wider platforms ( $\geq 5 \mathrm{~mm}$ ). Implants with internal hexagon connection may have a higher risk of fracture after implantoplasty compared to other connection designs such as external hexagon and conical connections. Other potential factors which may affect implant fracture resistance after implantoplasty include crown to implant ratio, implant material, and the amount of peri-implant bone loss. Within the limitation of in vitro studies, there is no clear evidence to demonstrate the effect of implantoplasty on implant fracture resistance. Methodological differences between the available studies did not allow for clear comparison between them. Furthermore, the limited amount of clinical reports of this resective procedure, in combination with patient and operator variability, affect the clinical assessment of this treatment modality.
\end{abstract}

Keywords: dental implant, implantoplasty, peri-implantitis, systematic review
Received:

22 October 2021

Revised:

22 November 2021

Accepted:

27 January 2022

Published Online:

4 March 2022

\section{How to cite this article:}

Goh, R. ., Tawse-Smith, A., Atieh, M. ., Duncan, W. ., Ma, S. ., \& Li, K. C. . The effect of implantoplasty on dental implant fracture resistance: a systematic review. IIUM Journal of Orofacial and Health Sciences, 3(1), 124-135. https://doi.org/10.31436/ijoh s.v3i1.113

\section{Article DOI:}

10.31436/ijohs.v3i1.113

\section{*Corresponding author}

\section{Address:}

Department of Oral Sciences, School of Dentistry, University of Otago, 310 Great King Street PO Box 56, Dunedin 9016, New Zealand

Telephone: +64-3-4703589

Email address:

andrew.tawse-

smith@otago.ac.nz

\section{Introduction}

Dental implants have shown to provide good functional and aesthetic outcomes for prosthetic rehabilitation of partially or fully edentulous patients (Berglundh et al., 2002). However, they are susceptible to plaque accumulation due to its non-shedding nature, which can lead to peri-implant inflammation such as peri-implant mucositis 
and peri-implantitis. A systematic review of the European and American population in 2015 found that the weighted mean prevalence of peri-implant mucositis and peri-implantitis were $43 \%$ and $22 \%$ respectively (Derks \& Tomasi, 2015).

Peri-implantitis can have devastating outcomes for patients as the supporting bone around the implant is affected. Various systematic reviews revealed that it was impossible to decontaminate implant surface completely through mechanical or chemical methods alone, while a combination of these methods yielded a better outcome (Louropoulou et al., 2014; Stavropoulos et al., 2019). These reviews also suggested that roughened implant surfaces initially introduced to increase the rate of osseointegration, have a higher tendency to accumulate and retain plaque which may negatively impact the management of peri-implant infection.

A multitude of non-surgical and surgical treatment protocols have been suggested to treat peri-implantitis around osseointegrated dental implants. A Cochrane review including nine randomized controlled trials showed insufficient evidence to support or refute the effectiveness of any specific treatment protocol for peri-implantitis (Esposito et al., 2012). There was also no consensus on surface decontamination methods for dental implants to obtain a predictable long-term result (Heitz-Mayfield \& Mombelli, 2014).

Surface decontamination is important to decrease the bacterial load around the dental implant and achieve a biocompatible surface for direct apposition of alveolar bone. Non-surgical debridement with or without antimicrobials has been shown to have limited efficacy when it is employed for peri-implantitis due to insufficient decontamination of the implant surface (Figuero et al., 2014). In this context, various methods to decontaminate the implant surface have been introduced such as mechanical, chemical debridement and laser therapy. Non-surgical debridement has been suggested as the pre-treatment phase of peri-implantitis management while surgical access should be considered when periimplantitis persists (Heitz-Mayfield \& Mombelli, 2014). Surgical therapy can be carried out through either a regenerative or resective approach depending on the defect morphology and the objective of the surgical intervention.

Implantoplasty is used as an adjunct to resective procedures to smoothen and remove contaminated implant surface in order to reduce or eliminate bacterial colonization on the implant surface (Stavropoulos et al., 2019). This procedure aims to achieve a relatively smooth implant surface and reduce the screw shape topography of the implant to facilitate ongoing implant maintenance. This has been successfully implemented by numerous clinicians and researchers to manage periimplantitis with good clinical and radiographic outcomes in areas with limited potential for bone regeneration due to the anatomy of the defect (Matarasso et al., 2014; Monje et al., 2021; Schwarz et al., 2013). Instrumentation of the implant surface will inevitably result in a narrower implant, which will likely decrease the maximum force it can withstand before fracturing. Therefore, the aim of this systematic review was to investigate the impact of implantoplasty on fracture resistance of dental implants.

\section{Materials and Methods}

This systematic review was conducted based on the guidelines given by the Preferred Reporting Items for Systematic Reviews and Meta-Analyses (PRISMA)(Moher et al., 2009), and Cochrane Collaboration (Higgins, 2021). This review aimed to address a focused question "Will implantoplasty on dental implants affect its fracture resistance?" using the PICO (participant/problem, intervention, comparison/control, and outcome) method (Miller \& Forrest, 2001).
P: Dental implants
I: Implantoplasty
C: Pristine implants
0: Fracture resistance 


\section{Type of Studies}

The following inclusion criteria were applied during literature search on studies without restriction in publication year: (a) In vitro studies; (b) reported the fracture resistance of dental implants before and after implantoplasty; (c) published in an English peer-reviewed journal; (d) available in fulltext.

\section{Search Strategies}

The following electronic databases were searched for ongoing and unpublished studies up to July 31, 2021: MEDLINE, Scopus and EMBASE (Table 1). The following search format was performed using Boolean operators: (implantoplasty OR implant surface modification) AND (fracture resistance OR fracture OR breakage). The bibliographies of all eligible articles were analysed for additional studies. Two calibrated reviewers (R.G and A.T.S) carried out the search for title, abstract, and full-text using the eligibility criteria in parallel. Opengrey.eu was used to search for grey literature. In case of uncertainty, the final decision was made by a third author (W.D). The reasons for excluding inapplicable studies were reported. The selected studies were imported into a reference managing program (EndNote 20; Clarivate Analytics, Philadelphia, PA, USA).

\section{Data Collection}

A data extraction form was designed and carried out by two reviewers (R.G and A.T.S) with the following aspects:
1. Study details: title, authors' names, contact address, study location, language and year of publication, published or unpublished data, source of funding

2. Dental implants: brand, diameter, length, material, instrumentation sequence, abutment-implant interface, number of implants in test and control groups, type of loading

3. Outcomes: fracture resistance of implants, location of implant fracture

\section{Assessment of Quality and Risk of Bias}

The In Vitro Critical Appraisal Tool (IV-CAT) was used to assess the risk of bias and study quality of the studies included in this review to ensure the validity of the assessment (de Vries, 2018).

\section{Results}

\section{Characteristics of the trial settings and investigators}

A total of 56 studies were identified from the initial electronic literature search (Figure 1). No additional studies were found through screening of the reference lists of these studies. Out of these 56 studies, only 15 were eligible for full-text evaluation after review of the abstracts and key words.

After full-text evaluation, six studies were excluded because they failed to meet the inclusion criteria. The remaining nine studies were further analysed in depth and included in this review.

Table 1. Electronic search strategy employed to identify relevant studies

$\begin{array}{lll}\text { Databases } & \text { Keywords } & \\ \text { Published studies } & \text { (implantoplasty OR implant surface } \\ \text { MEDLINE(PubMed), } & \text { modification) AND (fracture resistance OR } \\ \text { Scopus, Embase via Ovid } & \text { fracture OR breakage) } \\ \text { Unpublished studies } & \text { (implantoplasty OR implant surface } \\ \text { MetaRegister of controlled trials OpenGrey } & \text { modification) AND (fracture resistance OR } \\ \text { (www.opengrey.eu) (July 28, 2021) } & \text { fracture OR breakage) }\end{array}$




\section{Identification of studies via databases and registers}

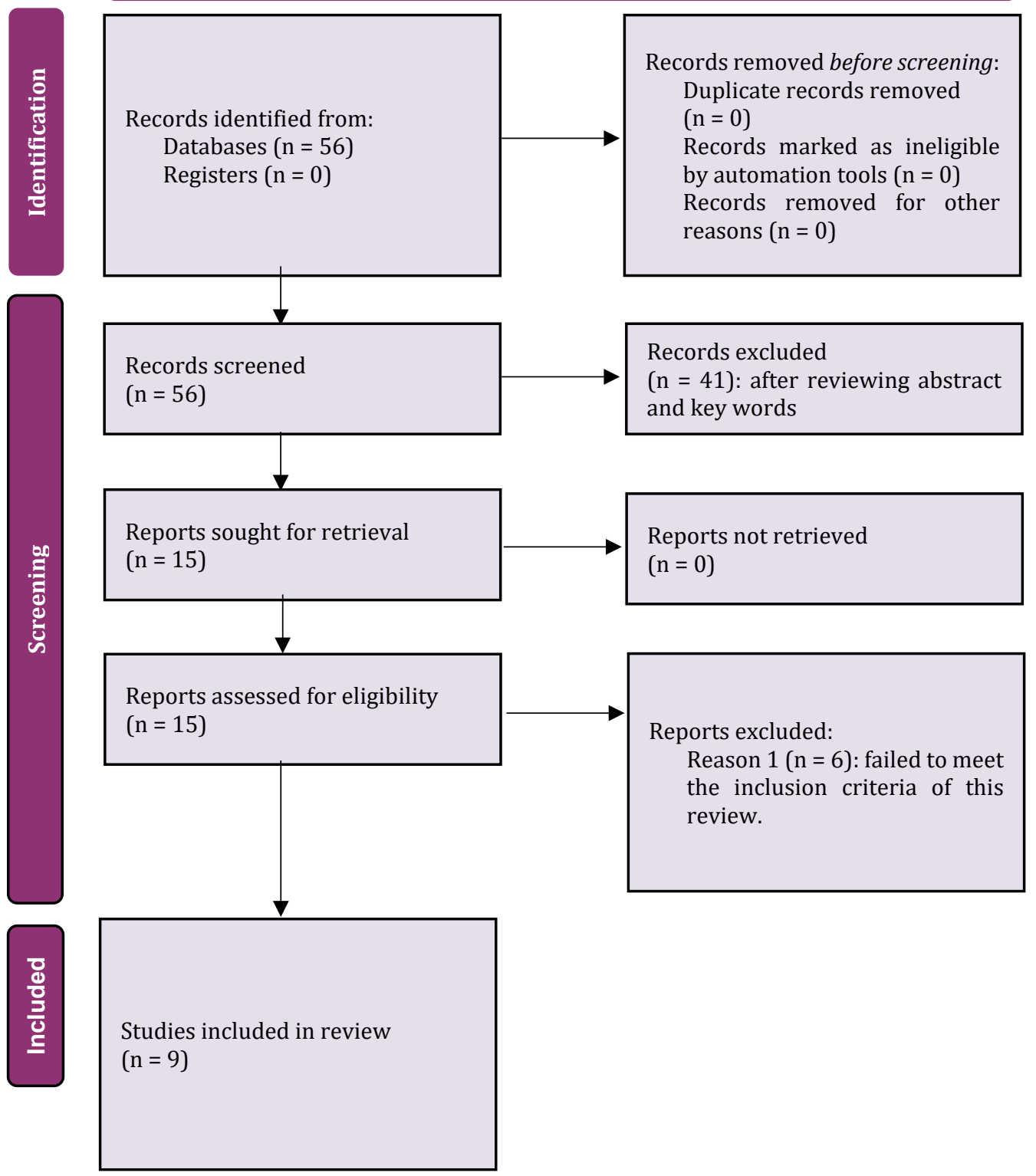

Figure 1. Flowchart of study selection 


\section{Risk of bias in included studies}

Using the In Vitro Critical Appraisal Tool (IVCAT), the included studies were assigned a low risk of bias and were recommended to be included in the review. All studies reported on primary in vitro research and utilised a framework for post-conduct appraisal.

\section{Incomplete outcome data and selective reporting}

Eight out of the nine studies obtained and reported all of the outcome data. One study which compared the fracture resistance of narrow and wide platform implants did not carry out the fracture resistance test on the $4.7 \mathrm{~mm}$ wide platform implants in the control group (Chan et al., 2013). This was because the wide implants in the test group fractured at the abutment screw and not at the implant body.

\section{Effects of interventions}

This review included nine studies with a total of 420 dental implants. The abutment connection design of these 420 dental implants consisted of 154 external connections, 230 internal connections, and 36 conical Morse taper connections. 86.7\% of the total implants were bone level fixtures made of titanium while the remaining $13.3 \%$ were tissue level fixtures made of titanium and zirconia. $57.7 \%$ of the titanium implants included in this review were made of grade IV titanium while the other $42.3 \%$ were made of grade $V$ titanium. Meta-analysis and quantitative analysis were not possible due to the limited number of included studies and heterogeneity of the extracted data.

\section{Outcome}

Two studies in this review investigated the effect of abutment connection design on the fracture resistance of dental implants (Camps-Font et al., 2020; Gehrke et al., 2016). The 2016 study by Gehrke et al. found that the conical Morse taper connection design provided the highest fracture resistance in $11 \mathrm{~mm}$ long, $4.0 \mathrm{~mm}$ regular diameter implants regardless of implantoplasty status. Implantoplasty in conical Morse taper connection implants reduced the fracture resistance by approximately $20 \%$ whilst external hexagon and internal hexagon implants experienced a more drastic decrease in fracture resistance after implantoplasty at approximately $37 \%$ and $40 \%$ respectively. Camps-Font et al. (2020) found conflicting results, whereby external hexagon connection implants had the highest fracture resistance in comparison to internal hexagon and conical Morse taper connection implants independent of implantoplasty in $3.5 \mathrm{~mm}$ narrow platform, $10 \mathrm{~mm}$ long implants. Regardless of the abutment connection design, there was a similar reduction of fracture resistance of approximately 29\% after implantoplasty for each of the designs.

Two out of the four studies with narrow diameter implants showed a statistically significant decrease in fracture resistance following implantoplasty (Bertl et al., 2020; Camps-Font et al., 2020). The exceptions, (Leitao-Almeida et al., 2020; Leitão-Almeida et al., 2021) both included groups with the greatest amount of exposed implant threads, $7.5 \mathrm{~mm}$, albeit with $15 \mathrm{~mm}$ long implants. Bertl et al. (2020) carried out an extensive study involving 112 dental implants of different materials, levels and diameters. The results indicated that implantoplasty reduced the fracture resistance of $3.3 \mathrm{~mm}$ narrow platform tissue level titanium implants the most. Likewise, the other study which investigated the effects of platform diameter on fracture resistance concluded that $3.75 \mathrm{~mm}$ diameter implants were more prone to fracture after implantoplasty compared to $4.7 \mathrm{~mm}$ diameter implants (Chan et al., 2013). An acknowledged limitation of this study was that the $4.7 \mathrm{~mm}$ diameter implants in the control group were not tested for fracture resistance. The rationale given was that the test implants 
fractured at the abutment screw, which did not influence the implant body. Out of the six studies which involved regular diameter implants, three studies (Chan et al., 2013; Costa-Berenguer et al., 2018; Sivolella et al., 2021) concluded that implantoplasty did not affect the fracture resistance while the other three (Bertl et al., 2020; Gehrke et al., 2016; Jorio et al., 2021) found a significant decrease in fracture resistance after implantoplasty.

Most of the articles used tungsten carbide burs with or without additional silicone polishing burs or Arkansas stones (Bertl et al., 2020; Camps-Font et al., 2020; Chan et al., 2013; Costa-Berenguer et al., 2018; Gehrke et al., 2016; Jorio et al., 2021; Leitao-Almeida et al., 2020; Leitão-Almeida et al., 2021; Sivolella et al., 2021). Two of the included studies performed the implantoplasty with diamond burs of various grits followed by polishers (Chan et al., 2013; Jorio et al., 2021). Bertl et al. (2020) and Gehrke et al. (2016) were the only studies which carried out computer-controlled implantoplasty to standardise the complete removal of implant threads for all of the tested implants.

Sivolella et al. (2021) investigated the difference between tungsten carbide burs with Arkansas stones and diamond sonic tips with Arkansas stone on fracture resistance. They found that the implants treated with diamond sonic tips were more conservative in terms of structure loss but did not have a significantly higher fracture resistance compared to the tungsten carbide burs group. Another study, which investigated the effect of different implantoplasty protocol on fracture resistance of implants, found that diamond burs and silicon carbide stone did not result in a statistically significant change in fracture resistance of implants (Jorio et al., 2021).

The study by Leitao-Almeida et al. (2021) suggested that a greater degree of bone loss is associated with a decrease in fracture resistance. The implants in the test group which underwent implantoplasty did not have a statistically significant difference in fracture resistance compared to the pristine implants in the control group.

Another study led by the same author, the year before, manipulated the crown to implant ratio by adjusting the height of the abutment (Leitao-Almeida et al., 2020). It was found that implantoplasty on an implant with a crown to implant ratio of 2.5:1 led to a decrease in fracture resistance in comparison with pristine implants (Table 6). Costa Berenguer et al., (2018) carried out a study on $4.1 \mathrm{~mm}$ diameter implants with the external hexagonal connection. The results indicated that implantoplasty did not significantly affect the fracture resistance in the tested implants.

A summary of the findings is presented in Table 2.

\section{Discussion}

Implant fracture is one of the most frustrating mechanical complications that can occur with dental implants. The effect of implantoplasty on fracture resistance of dental implants showed conflicting results which may be attributed to the different implants used in these studies. This review only included in vitro studies as it is impractical to perform implant fracture resistance tests on human subjects. To the author's knowledge, there are no in vivo studies available at present. In a clinical setting, implantoplasty is a lot more challenging for the operator due to the limited access intra-orally and blood affecting visibility. The results of these studies may not truly reflect on the fracture resistance of dental implants after implantoplasty in the oral cavity. More studies, designed to evaluate the short and long-term effects of implantoplasty in patients are needed. 
Table 2. Comparison between studies

\begin{tabular}{|c|c|c|c|c|c|c|c|c|}
\hline $\begin{array}{l}\text { Author } \\
\text { (year) }\end{array}$ & Brand & $\begin{array}{l}\text { Number } \\
\text { of } \\
\text { implants }\end{array}$ & $\begin{array}{l}\text { Diameter } \\
\text { x length }\end{array}$ & $\begin{array}{l}\text { Exposed } \\
\text { length }\end{array}$ & $\begin{array}{l}\text { Type of } \\
\text { test }\end{array}$ & $\begin{array}{l}\text { Abutment } \\
\text { connection }\end{array}$ & IP protocol & Results \\
\hline $\begin{array}{l}\text { Gehrke et } \\
\text { al., } 2016\end{array}$ & $\begin{array}{l}\text { Implacil De } \\
\text { Bortoli, São Paulo, } \\
\text { Brazil }\end{array}$ & 60 & $\begin{array}{l}4.0 \mathrm{~mm} x \\
11 \mathrm{~mm} \\
(60)\end{array}$ & $5 \mathrm{~mm}(60)$ & $\begin{array}{l}\text { Static } \\
(60)\end{array}$ & $\begin{array}{l}\text { External } \\
\text { hexagon }(20) \\
\text { Internal hexagon } \\
(20) \\
\text { Conical Morse } \\
\text { taper (20) }\end{array}$ & $\begin{array}{l}\text { Conical carbide cutter } \\
\text { burs in mechanical lathe } \\
\text { machine (model BV-20, } \\
\text { Ferrari, South Africa) }\end{array}$ & $\begin{array}{l}\text { IP reduced FR. Conical Morse } \\
\text { taper abutment connection had } \\
\text { the highest FR }\end{array}$ \\
\hline $\begin{array}{l}\text { Camps- } \\
\text { Font et al., } \\
2020\end{array}$ & $\begin{array}{l}\text { Biomimetic } \\
\text { Ocean, Avinent } \\
\text { Implant System, } \\
\text { Santpedor, Spain }\end{array}$ & 48 & $\begin{array}{l}3.5 \mathrm{~mm} x \\
10 \mathrm{~mm} \\
(48)\end{array}$ & $5 \mathrm{~mm}(48)$ & $\begin{array}{l}\text { Static } \\
(48)\end{array}$ & $\begin{array}{l}\text { External } \\
\text { hexagon (16) } \\
\text { Internal hexagon } \\
(16) \\
\text { Conical Morse } \\
\text { taper (16) }\end{array}$ & $\begin{array}{l}\text { Tungsten carbide bur, two } \\
\text { silicon carbide (SiC) } \\
\text { polishers }\end{array}$ & $\begin{array}{l}\text { IP reduced FR in narrow } \\
\text { implants. External hexagon } \\
\text { connection had the highest FR }\end{array}$ \\
\hline $\begin{array}{l}\text { Bertl et al., } \\
2020\end{array}$ & $\begin{array}{l}\text { Institut } \\
\text { Straumann AG, } \\
\text { Basel, } \\
\text { Switzerland }\end{array}$ & 112 & $\begin{array}{l}3.3 \mathrm{~mm} x \\
10 \mathrm{~mm} \\
(66) \\
4.1 \mathrm{~mm} \mathrm{x} \\
10 \mathrm{~mm} \\
(66)\end{array}$ & $3 \mathrm{~mm}(112)$ & $\begin{array}{l}\text { Dynamic, } \\
\text { then } \\
\text { static } \\
(112)\end{array}$ & $\begin{array}{l}\text { Internal hexagon } \\
(112)\end{array}$ & $\begin{array}{l}\text { Computer-controlled } \\
\text { instrumentation }\end{array}$ & $\begin{array}{l}\text { IP reduced FR in all implants } \\
\text { tested, but more so in narrow } \\
\text { titanium tissue level implants. }\end{array}$ \\
\hline $\begin{array}{l}\text { Chan et al., } \\
2013\end{array}$ & $\begin{array}{l}\text { TRI-Vent } \\
\text { Implants, TRI } \\
\text { Dental Implants, } \\
\text { Baar, Switzerland }\end{array}$ & 32 & $\begin{array}{l}3.75 \mathrm{~mm} x \\
10 \mathrm{~mm} \\
(16) \\
\\
4.7 \mathrm{~mm} \mathrm{x} \\
10 \mathrm{~mm} \\
(16)\end{array}$ & $5 \mathrm{~mm}(32)$ & $\begin{array}{l}\text { Static } \\
(32)\end{array}$ & $\begin{array}{l}\text { Internal hexagon } \\
(32)\end{array}$ & $\begin{array}{l}30-\text { and } 15-\mu \mathrm{m} \text { diamond } \\
\text { burs, Arkansas burs and } \\
\text { fine silicone polishers }\end{array}$ & $\begin{array}{l}\text { IP reduced FR in narrower } \\
3.75 \mathrm{~mm} \text { platform implants. }\end{array}$ \\
\hline $\begin{array}{l}\text { Sivolella et } \\
\text { al., } 2021\end{array}$ & $\begin{array}{l}\text { Zimmer Biomet, } \\
\text { Palm Beach } \\
\text { Gardens, Florida, } \\
\text { USA }\end{array}$ & 18 & $\begin{array}{l}4.0 \mathrm{~mm} \times \\
13 \mathrm{~mm} \\
(18)\end{array}$ & $6 \mathrm{~mm} \mathrm{(18)}$ & $\begin{array}{l}\text { Static } \\
(18)\end{array}$ & $\begin{array}{l}\text { External } \\
\text { hexagon (18) }\end{array}$ & $\begin{array}{l}\text { Two tungsten carbide bur } \\
\text { (decreasing toothing) (9) } \\
\text { Diamond sonic tips (9) }\end{array}$ & $\begin{array}{l}\text { IP did not affect FR. IP protocol } \\
\text { did not significantly affect FR }\end{array}$ \\
\hline
\end{tabular}




\begin{tabular}{|c|c|c|c|c|c|c|c|c|}
\hline $\begin{array}{l}\text { Jorio et al., } \\
2021\end{array}$ & $\begin{array}{l}\text { TRI-Vent } \\
\text { Implants, TRI } \\
\text { Dental Implants, } \\
\text { Baar, Switzerland }\end{array}$ & 50 & $\begin{array}{l}4.1 \mathrm{~mm} x \\
11 \mathrm{~mm} \\
(50)\end{array}$ & $6 \mathrm{~mm}(50)$ & $\begin{array}{l}\text { Cyclic, } \\
\text { then } \\
\text { static } \\
(40) \\
\text { Cyclic } \\
\text { only (10) }\end{array}$ & $\begin{array}{l}\text { Internal hexagon } \\
(50)\end{array}$ & $\begin{array}{l}\text { Diamond burs (106-, 40-, } \\
4 \mu \mathrm{m}), \text { Arkansas stone } \\
(10) \\
\text { SiC bur, Arkansas stone, } \\
\text { silicone polishers }(10) \\
\text { Diamond burs (30- and } \\
15 \mu \mathrm{m}), \text { Arkansas stone } \\
\text { and silicone polishers } \\
(10)\end{array}$ & $\begin{array}{l}\text { IP and cyclic loading decreased } \\
\text { FR. IP protocol did not affect FR }\end{array}$ \\
\hline & & & & & & & $\begin{array}{l}\text { Control (no } \\
\text { implantoplasty) (20) }\end{array}$ & \\
\hline $\begin{array}{l}\text { Leitao- } \\
\text { Almeida et } \\
\text { al., } 2021\end{array}$ & $\begin{array}{l}\text { Ocean E.C., } \\
\text { Avinent Implant } \\
\text { System S.L., } \\
\text { Santpedor, Spain }\end{array}$ & 32 & $\begin{array}{l}3.5 \mathrm{~mm} x \\
15 \mathrm{~mm} \\
(32)\end{array}$ & $\begin{array}{l}3 \mathrm{~mm}(16) \\
7.5 \mathrm{~mm}(16)\end{array}$ & $\begin{array}{l}\text { Static } \\
(32)\end{array}$ & $\begin{array}{l}\text { External } \\
\text { hexagon (32) }\end{array}$ & $\begin{array}{l}\text { Tungsten carbide bur, } \\
\text { two SiC polishers ( } 32 \text { ) }\end{array}$ & $\begin{array}{l}\text { IP did not affect FR in narrow } \\
\text { diameter dental implants. } \\
\text { Increase in exposed implant } \\
\text { surfaces led to decreased FR }\end{array}$ \\
\hline $\begin{array}{l}\text { Costa- } \\
\text { Berenguer } \\
\text { et al., } 2018\end{array}$ & $\begin{array}{l}\text { Titamax Smart } \\
\text { Cortical, Neodent, } \\
\text { Curitiba, Brazil }\end{array}$ & 20 & $\begin{array}{l}4.1 \mathrm{~mm} x \\
13 \mathrm{~mm} \\
(20)\end{array}$ & $6 \mathrm{~mm}(20)$ & $\begin{array}{l}\text { Static } \\
(20)\end{array}$ & $\begin{array}{l}\text { External } \\
\text { hexagon (20) }\end{array}$ & $\begin{array}{l}\text { Tungsten carbide bur, } \\
\text { two SiC polishers (20) }\end{array}$ & $\begin{array}{l}\text { IP did not affect FR in standard } \\
\text { diameter dental implants }\end{array}$ \\
\hline $\begin{array}{l}\text { Leitao- } \\
\text { Almeida et } \\
\text { al., } 2020\end{array}$ & $\begin{array}{l}\text { Ocean E.C., } \\
\text { Avinent Implant } \\
\text { System S.L., } \\
\text { Santpedor, Spain }\end{array}$ & 48 & $\begin{array}{l}3.5 \mathrm{~mm} x \\
15 \mathrm{~mm} \\
(48)\end{array}$ & $\begin{array}{l}7,5 \mathrm{~mm}(48) \\
\text { Crown to } \\
\text { implant } \\
\text { ratio: } \\
2: 1(16) \\
2.5: 1(16) \\
3: 1(16)\end{array}$ & $\begin{array}{l}\text { Static } \\
(48)\end{array}$ & $\begin{array}{l}\text { External } \\
\text { hexagon (48) }\end{array}$ & $\begin{array}{l}\text { Tungsten carbide bur, } \\
\text { two } \mathrm{SiC} \text { polishers }\end{array}$ & $\begin{array}{l}\text { IP reduced FR in implants with } \\
\text { CIR of } 2.5: 1 \text {. Mean total value of } \\
\text { all implants showed no } \\
\text { significant difference in FR after } \\
\text { IP }\end{array}$ \\
\hline
\end{tabular}


However, these in vitro studies still provided us with valuable insights into the effect of implantoplasty on the mechanical integrity of implants.

This review adopted the classification of implant diameter as proposed by Al-Johany et al. (2017), which described narrow platform diameter as $\geq 3.0 \mathrm{~mm}$ to $<3.75 \mathrm{~mm}$; regular diameter as $\geq 3.75 \mathrm{~mm}$ to $<5 \mathrm{~mm}$; and wide diameter as $\geq 5 \mathrm{~mm}$. A recent systematic review that looked at dental implant fracture reported that implants of narrower diameter have a higher incidence of fracture (Goiato et al., 2019). Similarly, narrower implants in this systematic review were found to be at a higher risk of fracture after implantoplasty, especially in the presence of significant bone loss around the implant. Narrow diameter implants have a smaller contact area between the implant surface and the alveolar bone, which may increase stress concentration in the implant body (Qian et al., 2009). Implantoplasty on narrow diameter implants will likely compromise its structural integrity by further reducing the implant diameter.

There is insufficient evidence to state whether external hexagon or conical Morse taper connection is more fracture resistant (Camps-Font et al., 2020; Gehrke et al., 2016). However, there is some indication that internal hexagon connection may be the weakest abutment connection design. Interestingly, the other studies which used implants with external hexagon connection showed that implantoplasty did not affect fracture resistance (Costa-Berenguer et al., 2018; Leitao-Almeida et al., 2020; LeitãoAlmeida et al., 2021; Sivolella et al., 2021). Internal hexagon connection implants, on the other hand, showed a decrease in fracture resistance after implantoplasty in two studies. One study showed a reduction in narrow implants only (Chan et al., 2013), and the other study acknowledged a reduction in regular diameter implants (Jorio et al., 2021). A possible explanation could be that implantoplasty further reduces the thickness of the thin lateral fixture wall at the neck of the implant where the fixture connects to the internal connection abutment, which compromises the integrity of the implant body. This suggests that external hexagon connection implants that have undergone implantoplasty may be less likely to fracture compared to other connection designs.

Implantoplasty instrumentation protocol may not have a significant effect on the fracture resistance but diamond sonic tips seem to be more conservative in nature, albeit more time consuming (Sivolella et al., 2021). Two of the studies utilised computercontrolled instrumentation (Bertl et al., 2020; Gehrke et al., 2016). This ensured that the implantoplasty done on each implant was standardised with identical pressure and surface roughness. However, as implantoplasty has to be performed by a trained operator in a clinical setting, the other studies in this review may have higher clinical relevance because it allows for variability amongst clinicians. Bertl (2020), as well as Jorio (2021) carried out cyclic loading on the implants prior to static loading until failure to better simulate masticatory forces. Both studies found that implantoplasty resulted in a decrease in fracture resistance. Cyclic loading on implants can increase the stress at the interface between implant and bone, which affect the mechanical properties of the implant (Chen et al., 2010).

Most implant fractures were also found to occur at the platform, which indicates that mechanical stress may be concentrated in this zone, especially when the amount of bone loss increases. Narrow implants irrespective of platform connection included in this review demonstrated a tendency to fracture at the platform level. However, the risk of implant body and prosthetic screw fracture increased after implantoplasty (Camps-Font et al., 2020; Leitao-Almeida et al., 2020; Leitão-Almeida et al., 2021). Similar findings were reported for regular diameter implants, which showed weakening of the implant body following implantoplasty (Costa-Berengeur et al., 2018). Gehrke et al.(2016) on the other hand found that in regular diameter dental implants with external and internal hexagonal connections, fracture is similarly more likely to occur at the platform level, but 
with less risk of damage to the abutment and implant body after implantoplasty. The study by Bertl et al. (2020) focusing on 112 Straumann implants indicated that 110 of the implants of various diameter $(3.3 \mathrm{~mm}$ and $4.1 \mathrm{~mm}$ ), material (grade IV titanium and titanium-zirconia) and level (bone and tissue) fractured at the implant body irrespective of implantoplasty status. The remaining two were bone level regular diameter titanium implants without implantoplasty which fractured at the neck. This study was the only one in this review which compared implants with different levels and materials. They stated that grade IV titanium tissue level implants were more likely to fracture compared to titaniumzirconia alloy bone level implants.

One study documented a difference in fracture resistance due to the degree of simulated bone loss around the implant (Leitão-Almeida et al., 2021). This sparse evidence suggests that the fracture resistance of dental implants decrease as the amount of bone loss around the implant increases (Leitão-Almeida et al., 2021). This study is similar to earlier work done by the same authors (Leitao-Almeida et al., 2020). In this earlier study, a crown to implant ratio of 2.5:1 was significantly less resistant to fracture after implantoplasty compared to ratios of 2:1 and 3:1 (Leitao-Almeida et al., 2020). A study which utilised finite element analyses to evaluate the effects of implantoplasty on implants of different bone levels observed that stress on the implant increased as the bone level decreased up to approximately half the length of the implant (Tribst et al., 2017). With further bone loss past this point, the stress on the implant decreased with decreasing implant bone levels, and the micro strain exerted on the bone tissue drastically increased. This study also suggested that implantoplasty resulted in an increase in stress concentration on the implant, which implied that the critical stress point will be achieved earlier, contributing to implant fracture.

The majority of the included studies employed a fatigue testing protocol according to the ISO 14801:2007 guidelines, as revised in 2016 (Bertl et al., 2020; Camps-
Font et al., 2020; Costa-Berenguer et al., 2018; Jorio et al., 2021; Leitao-Almeida et al., 2020; Leitão-Almeida et al., 2021; Sivolella et al., 2021). It is important to note that this guideline specifically states that while it simulates the functional loading of the dental implant body and associated prosthetic component under worst case conditions, it is not applicable for predicting the in vivo performance of an implant.

There are many other factors at play in these studies which can affect the results and add to the observed heterogeneity amongst the studies. It is difficult to make a complete extrapolation of these findings in a real clinical scenario as patients differ in the degree of edentulism, being either fully or partially edentulous. For partially edentulous patients, edentulism location, prosthodontic rehabilitation and force distribution differ significantly between patients which will clearly affect the fracture resistance of dental implants (Stavropoulos et al., 2019). More studies in this area are needed to further understand the various factors associated with a change in fracture resistance after implantoplasty.

\section{Conclusion}

This systematic review showed that the true impact of implantoplasty on fracture resistance of dental implants is not clear due to multiple potential confounding factors such as the extent of bone loss, implant diameter and connection design. However, within the limitations of this review, the results revealed that narrow platform implants with internal hexagon connection may be more susceptible to fracture. To overcome this limitation of narrow diameter implants, the use of titanium-zirconia alloy and bone level implants should be considered to increase the structural strength of the implants. A small number of clinical cases with implantoplasty, patient and operator variability, and ethical implications of fracture resistance evaluations will affect potential clinical assessment of this treatment modality. Clinicians are advised to take these into consideration during treatment planning, 
especially for patients with increased risk of peri-implantitis.

\section{References}

Al-Johany, S. S., Al Amri, M. D., Alsaeed, S., \& Alalola, B. (2017). Dental Implant Length and Diameter: A Proposed Classification Scheme. Journal of Prosthodontics, 26(3), 252-260.

Al-Omiri, M., Hantash, R. A., \& Al-Wahadni, A. (2005). Satisfaction with dental implants: a literature review. Implant Dentistry, 14(4), 399-406.

Albrektsson, T., Dahlin, C., Jemt, T., Sennerby, L., Turri, A., \& Wennerberg, A. (2014). Is marginal bone loss around oral implants the result of a provoked foreign body reaction? Clinical Implant Dentistry and Related Research, 16(2), 155-165.

Berglundh, T., Persson, L., \& Klinge, B. (2002). A systematic review of the incidence of biological and technical complications in implant dentistry reported in prospective longitudinal studies of at least 5 years. Journal of Clinical Periodontology, 29 Suppl 3, 197-212; discussion 232-193.

Bertl, K., Isidor, F., von Steyern, P. V., \& Stavropoulos, A. (2020). Does implantoplasty affect the failure strength of narrow and regular diameter implants? A laboratory study. Clinical Oral Investigations.

Blomberg, S. (1985). Psychiatric aspects of patients treated with bridges on osseointegrated fixtures. Swedish Dental Journal. Supplement, 28, 183-192. https://www.ncbi.nlm.nih.gov/pubmed/3864260

Camps-Font, O., Gonzalez-Barnadas, A., Mir-Mari, J., Figueiredo, R., Gay-Escoda, C., \& ValmasedaCastellon, E. (2020). Fracture resistance after implantoplasty in three implant-abutment connection designs. Medicina Oral, Patologia Oral, Cirugia Bucal, 25(5), e691-e699.

Chan, H. L., Oh, W. S., Ong, H. S., Fu, J. H., Steigmann, M., Sierraalta, M., \& Wang, H. L. (2013). Impact of implantoplasty on strength of the implantabutment complex. The International Journal of Oral \& Maxillofacial Implants, 28(6), 1530-1535.

Chen, L., Guo, X., Li, Y., \& Li, T. (2010). Finite element analysis for interfacial stress and fatigue behaviors of biomimetic titanium implant under static and dynamic loading conditions. Zhong Nan Da Xue Xue Bao Yi Xue Ban, 35(7), 662-672.

Costa-Berenguer, X., Garcia-Garcia, M., SanchezTorres, A., Sanz-Alonso, M., Figueiredo, R., \& Valmaseda-Castellon, E. (2018). Effect of implantoplasty on fracture resistance and surface roughness of standard diameter dental implants. Clinical Oral Implants Research, 29(1), 46-54.

de Vries, R. W., P. (2018). In Vitro Critical Appraisal Tool (IV-CAT_: Tool Development Protocol (1.0.0) Zenodo

Derks, J., \& Tomasi, C. (2015). Peri-implant health and disease. A systematic review of current epidemiology. Journal of Clinical Periodontology, 42 Suppl 16, S158-171.

Esposito, M., Grusovin, M. G., \& Worthington, H. V. (2012). Treatment of peri-implantitis: what interventions are effective? A Cochrane systematic review. European Journal of Oral Implantology, 5 Suppl, S21-41.

Figuero, E., Graziani, F., Sanz, I., Herrera, D., \& Sanz, M. (2014). Management of peri-implant mucositis and peri-implantitis. Periodontology 2000, 66(1), 255273.

Gehrke, S. A., Aramburu Junior, J. S., Dedavid, B. A., \& Shibli, J. A. (2016). Analysis of Implant Strength After Implantoplasty in Three Implant-Abutment Connection Designs: An In Vitro Study. The International Journal of Oral \& Maxillofacial Implants, 31(3), e65-70.

Goiato, M. C., Andreotti, A. M., dos Santos, D. M., Nobrega, A. S., de Caxias, F. P., \& Bannwart, L. C. (2019). Influence of length, diameter and position of the implant in its fracture incidence: A Systematic Review. Journal of Dental Research, Dental Clinics, Dental Prospects, 13(2), 109-116.

Heitz-Mayfield, L. J., \& Mombelli, A. (2014). The therapy of peri-implantitis: a systematic review. The International Journal of Oral \& Maxillofacial Implants, 29 Suppl, 325-345.

Higgins, J. G., S. (2021). Cochrane Handbook for Systematic Reviews for Interventions Version 6.2

Howe, M. S., Keys, W., \& Richards, D. (2019). Long-term (10-year) dental implant survival: A systematic review and sensitivity meta-analysis. Journal of Dentistry, 84, 9-21.

Jorio, I. C., Stawarczyk, B., Attin, T., Schmidlin, P. R., \& Sahrmann, P. (2021). Reduced fracture load of dental implants after implantoplasty with different instrumentation sequences. An in vitro study. Clinical Oral Implants Research.

Leitao-Almeida, B., Camps-Font, O., Correia, A., MirMari, J., Figueiredo, R., \& Valmaseda-Castellon, E. (2020). Effect of crown to implant ratio and implantoplasty on the fracture resistance of narrow dental implants with marginal bone loss: an in vitro study. BMC Oral Health, 20(1), 329.

Leitão-Almeida, B., Camps-Font, O., Correia, A., MirMari, J., Figueiredo, R., \& Valmaseda-Castellón, E. (2021). Effect of bone loss on the fracture resistance of narrow dental implants after implantoplasty. An in vitro study. Medicina Oral, Patologia Oral, Cirugia Bucal.

Lindhe, J., Meyle, J., \& Group, D. o. E. W. o. P. (2008). Peri-implant diseases: Consensus Report of the Sixth European Workshop on Periodontology. Journal of Clinical Periodontology, 35(8 Suppl), 282-285.

Louropoulou, A., Slot, D. E., \& Van der Weijden, F. (2014). The effects of mechanical instruments on contaminated titanium dental implant surfaces: a systematic review. Clinical Oral Implants Research, 25(10), 1149-1160.

Matarasso, S., Iorio Siciliano, V., Aglietta, M., Andreuccetti, G., \& Salvi, G. E. (2014). Clinical and radiographic outcomes of a combined resective and regenerative approach in the treatment of peri-implantitis: a prospective case series. Clinical Oral Implants Research, 25(7), 761-767.

Miller, S. A., \& Forrest, J. L. (2001). Enhancing your practice through evidence-based decision making: PICO, learning how to ask good questions. Journal of Evidence-Based Dental Practice, 1(2), 136-141. 
Moher, D., Liberati, A., Tetzlaff, J., Altman, D. G., \& Group, P. (2009). Preferred reporting items for systematic reviews and meta-analyses: the PRISMA statement. PLOS Medicine, 6(7), e1000097.

Monje, A., Pons, R., Amerio, E., Wang, H. L., \& Nart, J. (2021). Resolution of peri-implantitis by means of implantoplasty as adjunct to surgical therapy: A retrospective study. Journal of Periodontology.

Moraschini, V., Poubel, L. A., Ferreira, V. F., \& Barboza Edos, S. (2015). Evaluation of survival and success rates of dental implants reported in longitudinal studies with a follow-up period of at least 10 years: a systematic review. International Journal of Oral and Maxillofacial Surgery, 44(3), 377-388.

Qian, L., Todo, M., Matsushita, Y., \& Koyano, K. (2009). Effects of implant diameter, insertion depth, and loading angle on stress/strain fields in implant/jawbone systems: finite element analysis. The International journal of oral and maxillofacial implants, 24(5), 877-886.

Schwarz, F., Hegewald, A., John, G., Sahm, N., \& Becker, J. (2013). Four-year follow-up of combined surgical therapy of advanced peri-implantitis evaluating two methods of surface decontamination. Journal of Clinical Periodontology, 40(10), 962-967.

Sivolella, S., Brunello, G., Michelon, F., Concheri, G., Graiff, L., \& Meneghello, R. (2021). Implantoplasty: Carbide burs vs diamond sonic tips. An in vitro study. Clinical Oral Implants Research, 32(3), 324336.

Stavropoulos, A., Bertl, K., Eren, S., \& Gotfredsen, K. (2019). Mechanical and biological complications after implantoplasty-A systematic review. Clinical Oral Implants Research, 30(9), 833-848.

Tribst, J. P. M., Dal Piva, A. M. O., Shibli, J. A., Borges, A. L. S., \& Tango, R. N. (2017). Influence of implantoplasty on stress distribution of exposed implants at different bone insertion levels. Braz Oral Research, 31, e96. 